\title{
The Locus of Innovation in Small and Medium-sized Firms: The Importance of Social Capital and Networking in Innovative Entrepreneurship
}

\author{
Willem Hulsink, Tom Elfring and Wouter Stam
}

\begin{tabular}{|l|l|}
\hline \multicolumn{2}{|l|}{ ERIM REPORT SERIES RESEARCH IN MANAGEMENT } \\
\hline ERIM Report Series reference number & ERS-2008-041-ORG \\
\hline Publication & July 2008 \\
\hline Number of pages & 47 \\
\hline Persistent paper URL & http://hdl.handle.net/1765/12873 \\
\hline Email address corresponding author & whulsink@rsm.nl \\
\hline Address & Erasmus Research Institute of Management (ERIM) \\
& RSM Erasmus University / Erasmus School of Economics \\
& Erasmus Universiteit Rotterdam \\
& P.O.Box 1738 \\
& 3000 DR Rotterdam, The Netherlands \\
& Phone: + 31 10 408 1182 \\
& Fax: + 31 10 408 9640 \\
& Email: info@erim.eur.nl \\
& Internet: www.erim.eur.nl \\
\hline
\end{tabular}

Bibliographic data and classifications of all the ERIM reports are also available on the ERIM website: www.erim.eur.nl 


\section{RESEARCH IN MANAGEMENT}

\begin{tabular}{|c|c|}
\hline \multicolumn{2}{|c|}{ ABSTRACT AND KEYWORDS } \\
\hline Abstract & $\begin{array}{l}\text { Social networks matter in the innovation processes of young and small firms, since 'innovation } \\
\text { does not exist in a vacuum (Van De Ven, 1986: 601).' The contacts a firm has could both } \\
\text { generate advantages for further innovation and growth, and disadvantages leading to inertia and } \\
\text { stagnation. In the first case the existing social network or the new business contact provides } \\
\text { opportunities furthering eventual success, in the second case, the existing network or the new } \\
\text { business contacts turns out to have a constraining or even detrimental effect on performance. } \\
\text { The search and use of social capital is driven by goal-specificity: it only includes those ties that } \\
\text { help the actor in the attainment of particular goals. Most of the research so far has been } \\
\text { deliberately or unwillingly one-sided, by for instance only looking at entrepreneurial firms in } \\
\text { dynamic industries (or more specifically, start-ups in the high-tech industries). Or selective } \\
\text { attention has been paid to either the internal sources or the external contacts to trigger } \\
\text { innovation. And when a conclusive study has been conducted into investigating both the effect of } \\
\text { internal and external ties on innovation, the sample often includes large and established } \\
\text { companies and managers (instead of entrepreneurs and smaller firms, as what we are interested } \\
\text { in). The main line of reasoning in this paper is as follows. In the first section we discuss the key } \\
\text { network concepts, such as, social capital, relational embeddedness (strong and weak ties), } \\
\text { structural embeddedness (i.e. structural holes). Section two deals with innovation and the central } \\
\text { role of knowledge in the discovery and realisation of innovations. Social networks and its } \\
\text { potential for knowledge brokering appear to be important and therefore the last section focuses } \\
\text { on the relationship between particular network characteristics and innovation. }\end{array}$ \\
\hline Free Keywords & $\begin{array}{l}\text { entrepreneurship, innovation, social capital, networking, small- and medium-sized firms, } \\
\text { James Dyson }\end{array}$ \\
\hline Availability & $\begin{array}{l}\text { The ERIM Report Series is distributed through the following platforms: } \\
\text { Academic Repository at Erasmus University (DEAR), DEAR ERIM Series Portal } \\
\text { Social Science Research Network (SSRN), SSRN ERIM Series Webpage } \\
\text { Research Papers in Economics (REPEC), REPEC ERIM Series Webpage }\end{array}$ \\
\hline Classifications & $\begin{array}{l}\text { The electronic versions of the papers in the ERIM report Series contain bibliographic metadata } \\
\text { by the following classification systems: } \\
\text { Library of Congress Classification, (LCC) LCC Webpage } \\
\text { Journal of Economic Literature, (JEL), } \underline{\text { JEL Webpage }} \\
\text { ACM Computing Classification System CCS Webpage } \\
\text { Inspec Classification scheme (ICS), ICS Webpage }\end{array}$ \\
\hline
\end{tabular}




\title{
The locus of innovation in small and medium-sized firms:
}

\author{
The importance of social capital and networking in innovative \\ entrepreneurship
}

Willem Hulsink, Tom Elfring, Wouter Stam

\begin{abstract}
Key words: Entrepreneurship, Innovation, social capital, networking, small- and medium-sized firms, James Dyson
\end{abstract}

\begin{abstract}
Social networks matter in the innovation processes of young and small firms, since 'innovation does not exist in a vacuum (Van De Ven, 1986: 601).' The contacts a firm has could both generate advantages for further innovation and growth, and disadvantages leading to inertia and stagnation. In the first case the existing social network or the new business contact provides opportunities furthering eventual success, in the second case, the existing network or the new business contacts turns out to have a constraining or even detrimental effect on performance. The search and use of social capital is driven by goal-specificity: it only includes those ties that help the actor in the attainment of particular goals. Most of the research so far has been deliberately or unwillingly one-sided, by for instance only looking at entrepreneurial firms in dynamic industries (or more specifically, start-ups in the high-tech industries). Or selective attention has been paid to either the internal sources or the external contacts to trigger innovation. And when a conclusive study has been conducted into investigating both the effect of internal and external ties on innovation, the sample often includes large and established companies and managers (instead of entrepreneurs and smaller firms, as what we are interested in). The main line of reasoning in this paper is as follows. In the first section we discuss the key network concepts, such as, social capital, relational embeddedness (strong and weak ties), structural embeddedness (i.e. structural holes). Section two deals with innovation and the central role of knowledge in the discovery and realisation of innovations. Social networks and its potential for knowledge brokering appear to be important and therefore the last section focuses on the relationship between particular network characteristics and innovation.
\end{abstract}




\section{Introduction}

The economist Giovanni Dosi (1988: 1132) made the point that innovation is primarily a process built on the activation of the specific internal capabilities, cumulative routines and implicit or tacit knowledge of established corporations: 'one needs to have substantial inhouse capacity in order to recognise, evaluate, negotiate, and finally adapt the technology potentially available from others.' The driving forces behind innovation in these larger firms are internal employees and inputs from $R \& D$, manufacturing or sales units, etc. Others have stressed the mobilization of external resources from companies' environment, such as direct or indirect links with leading knowledge institutions, dedicated suppliers, customers etc. Oerlemans, Meeus and Boekema (1998) have argued that, in order to explain innovative performance, both internal and external resources need to be included. Entrepreneurial firms suffering from strong internal resource constraints or competency gaps may benefit from external linkages with technology partners, investors and/or service providers, acting as real complementors. Similarly, Lee, Lee and Pennings (2001) argued that networking with external parties providing complementary resources contributes to a further accumulation of internal capabilities. In this study, we follow their advice and attempt to answer the following question: which ties and network position matter when it comes to complementing internal competences in order to be innovative? In other words, we investigate the role networks play in finding external knowledge that can be combined with internal competences to realize new combinations.

Our study involves an analysis of whether social and economic networks influence innovation processes or, as Oerlemans, Meeus \& Boekema (1998) put it: 'Do networks matter for innovation?', with an exclusive focus on the creation and implementation of new ideas, processes and products within and by small- and medium-sized firms. These firms may vary in their entrepreneurial make-up, for instance in terms of their focus in terms of 
craftsmanship/product, whether they are opportunity-oriented or growth-oriented, and whether they are invention-based or knowledge-based. Smith \& Miner (1983) were among the first to distinguish different types of entrepreneurs, firms and managerial motivations. Initially, they identified the 'craftsman' and the 'opportunistic entrepreneur', as well as the organizational vehicles with which they are associated, the rigid and the adaptive firm structure respectively. While the craftsman usually has a limited education and training and a low social awareness and involvement, finds it difficult to interact with the social environment and operates within a limited time horizon, the opportunistic entrepreneur is known for his breadth in education and training, a high social awareness and involvement, a confidence in his ability to deal with the social environment and an awareness of and orientation towards the future. Miner and Smith, together with Bracker (1992), later identified a third category, the inventorentrepreneur, who focuses on obtaining patents and making new products. Whereas the craftsman is in the business of making a better product and the opportunistic entrepreneur is trying to build a better company, the inventor-entrepreneur lives to invent: his or her sole purpose in doing business is discovering new things and generating new products.

The starting point in our study is the assumption that social networks play an important role in the innovation process. To promote new products, and to develop new markets and new ways of producing and distributing, the founders of new firms as well as corporate entrepreneurs who engage in strategic initiatives in established companies can draw upon extensive and rich personal and business contacts (Stam \& Elfring, 2008; Floyd \& Woolridge, 1999). These benefits stem from privileged access to knowledge, financial capital, legitimacy and other resources that facilitate entrepreneurial behaviour and performance. The efficient or effective use of social networks has been recognized as a key driver in the promotion and implementation of innovation. After all, 'innovation does not exist in a vacuum (Van De Ven, 1986: 601).' Especially in new and small and medium-sized enterprises (SMEs), innovation 
processes usually transcend the boundaries of a firm. External parties may be sources of inspiration and/or they may contribute to the implementation of innovations. Many SMEs have insufficient organizational resources, knowledge or capabilities to develop innovations by themselves. These are all reasons why smaller firms may seek larger parties for the purposes of collaboration.

On the one hand, the contacts a firm has can generate advantages for further innovation and growth, while on the other hand they may lead to inertia and stagnation, for instance by being locked out from where the action is, taking the wrong advice or choosing the wrong partner or being locked into a leading firm, sector or cluster in decline. In the former case, the existing social network or new business contact provides opportunities that may eventually lead to success, whereas in the latter case, the existing network or new business contacts turn out to have a constraining or even detrimental effect on a firm's performance. The search and use of social capital is driven by goal-specificity: it only includes those ties that help the actor attain particular goals. To date, most studies have been deliberately or accidentally one-sided, for instance by focusing exclusively on entrepreneurial firms in dynamic industries (or more specifically on start-ups in the high-tech industries), or by paying selective attention either to the internal sources or to the external contacts to trigger innovation. In cases where the impact of internal and external ties on innovation have both been examined, the sample often includes large and established companies and managers (rather than entrepreneurs and smaller firms, on which our study focuses).

Before taking a more detailed look at relevant existing studies, we formulate a number of basic assumptions that indicate our starting point and research approach. First of all, networks do not make or break ideas, products, people or firms, nor do they have any discretionary power. By opening up opportunities or pre-selecting a life course of firms and by imposing constraints on their discretion, networks provide a context for social action. 
Secondly, the level of analysis in this study is the entrepreneur and/or his firm, and their personal and business-related networks. Although in the ideation and formation phase, the entrepreneur and his company are a single entity, when a company starts to grow and hires new people, they start to diverge. In that case, the social network of the entrepreneur and that of his firm may be different. In addition, employees infuse the company with additional social capital and may bring useful contacts, such as leads to new suppliers, customers and knowledge institutions.

Thirdly, there is the temporal dimension of social networks. Exchanging information, building trust and pooling resources are not things that develop overnight, but networking is an ongoing process. Social networks gradually unfold (and sometimes diminish) over a long period of time, only occasionally interrupted by events or incidents such as opportunities for or threats to the firm that require decisive and immediate social action. Too often, in network analysis a static view of social capital and network development in adopted, while the time span used is too short. This may result in a bias in which infrequent relations may be overlooked and latent or dormant ties may be mistakenly treated as still active. Networking is a dynamic process, in which latent ties may become manifest, and manifest ties may become dormant, depending on the situation in which the firm finds itself and the urgency of action (Hite, 2003). Old bonds, new ties or dormant contacts may be activated, surpassing the existing network to meet the need and support the survival and growth of the company.

Another observation is that social networking is not necessarily a good and positive thing. Many researchers argue that social networks, a term that is often used interchangeably with related terms like (inter-organizational) trust and reciprocity, are to be preferred to the chaotic and fluid market place and rigid bureaucracies. Falling back on one's friends and relatives, finding new leads and resources through former colleagues, using external consultants, participating in trade fairs, contacting other local entrepreneurs and attending 
seminars are all useful in the search for information and mobilization of resources. However, it is not the quantity of the ties and the amount of networking per se that is relevant. Rather, it is the quality, objective and timing of the social networking that are crucial in the evolution of a firm or entrepreneur. In addition to the potential danger of network overload, network closure and lock-in can also be seen as less positive sides of networks. Uzzi (1997) has, for instance, referred to the dangers of the 'overembeddedness' of relationships, in which firms are insulated from new knowledge and find it harder to adapt to new circumstances.

The main line of reasoning in this study is as follows. In the following section we discuss the key network concepts, including social capital, relational embeddedness (strong and weak ties), structural embeddedness (the so-called 'structural holes' in the large social community). Next, we address innovation and the central role of knowledge in the discovery and realization of innovations. Because networks and their potential for knowledge-brokering appear to be important, we close by focusing on the relationship between particular network characteristics and innovation.

\section{Intermezzo: The locus of innovative entrepreneurship at Dyson company ${ }^{1}$}

The cult of the lone creative inventor and the innovation process as a linear trajectory from invention into a marketable product are two persistent myths in the field of innovative entrepreneurship. In today's world, however, there are few solitary geniuses and glorious Eureka moments. Innovators put inventions together from what they already know and recombine existing ideas and practices from other industries and innovators (Hargadon, 2003). Anyone assigning significant innovations to extraordinary individuals and seeing a successful market diffusion of a particular product as a direct consequence of some of its superior characteristics fails to take the importance of the self-belief and persistence, the skill

\footnotetext{
${ }^{1}$ This intermezzo is based on the following sources: James Dyson's autobiography (Dyson, 1997), and Jones \& Conway (2004).
} 
sets and the social capital of the 'lone inventor' into account. Rather than individualistic phenomena, innovation and entrepreneurship are extra-individual and collaborative activities: 'historical studies clearly show that most innovations are collective achievements of the efforts of many actors working over an extended period of time, often in parallel and independent locations' (Van de Ven 1993: 212).

Although some may seem him as a lone creative designer and entrepreneurial genius, James Dyson, the traditional inventor-entrepreneur who built his own company to manufacture, market and sell his alternative vacuum cleaner, basically owed his success to sheer hard work, relentless networking and strategic partnering, and maybe a fair bit of luck as well. As a heroic start-up entrepreneur with a breakthrough product, the bag-less dual cyclone vacuum cleaner, Dyson had to take on the incumbent companies in the vacuum cleaning market, namely Hoover and Electrolux. He had to design an appropriate business model, mobilize the resources he needed for the further development and effectively secure a leading position in the British market. Within five years after founding his company, his mission was accomplished: Dyson was number one in the UK market and his company had grown to 900 people between 1992 and 1997. Although everyone now knows that the Dyson story has a happy ending, this was by no means clear from the start: he was the vacuum cleaner market's David who had worked for over a decade on the development of an alternative and innovative design for the vacuum cleaner, and who now took on a number of Goliaths, who made lots of money selling bags, trying to gain a foothold in that lucrative market. A manager of a large company tried to discourage him and warned him of the R\&D and market power of the large companies: 'But James, your idea can't be any good. If there was a better kind of vacuum cleaner, Hoover or Electrolux would have invented it (in Dyson 1997: 117).' As a small and struggling entrepreneur trying to develop and sell a radical innovation, Dyson had to overcome major technical, strategic, financial and legal hurdles to compete with the big 
companies with their broad knowledge base, an in-place distribution system and deep financial pockets. One of the tools he used was his social capital, including his friends, relatives and contacts from his earlier (professional) life, and ties he mobilized and acquired through all kinds of business meetings and serendipitous encounters.

James Dyson attended the Royal College of Art (RCA) in London and studied industrial design. Throughout his professional and business career, he stayed in touch with the RCA: in the early 1990s, he hired four designers straight out of the RCA to work in his startup company, and in the late 1990s, he employed some 20 RCA graduates. After graduating from the RCA, he began working for the entrepreneur Jeremy Fry and his company Rotork, a valve manufacturer, on the Sea Truck project. As his employer, and later as his mentor, Fry became very influential in Dyson's career. Almost from the very beginning, Fry gave Dyson carte blanche, allowing him to run the Sea Truck business almost by himself: Rotork, a manufacturer of motorized valve actuators for pipelines, paid Dyson 300 pounds for the design, and a special subsidiary was set up to make and sell the Sea Truck. The experience taught Dyson a great deal about the relationship between selling and designing, especially in the capital goods market. He already understood the importance of direct sales and founder involvement in marketing (1997: 236): 'if you make something, sell it yourself.' Dyson was also inspired by earlier great industrial designers, like Buckminster Fuller, Alec Issigonis and Isambard Kingdom Brunel.

While working on projects alongside the Sea Truck project at Rotork, Dyson developed the idea for the Ballbarrow, as an alternative to the existing wheelbarrow. Because this was not one of Rotork's core projects, Dyson decided, with Jeremy Fry's blessing, to leave the company to try and market his invention on the business and/or consumer market. For that purpose, he founded Kirk-Dyson, together with, Stuart Kirkwood, his brother in law. Later joined by an investor and professional management and designers, the company 
developed a relatively successful line of garden-oriented products. The Ballbarrow quickly became a success on the consumer market, thanks to an organized sales, media and free publicity effort, in which, besides a catchy campaign slogan devised by James Dyson himself ('the Ballbarrow is here'), a former Miss Great Britain and a number of business journalists played an active part (they were mobilized after a casual encounter or a directed call for press coverage)

Disaster struck when Dyson found out that the idea for the Ballbarrow and most of his marketing campaign (e.g. slogan, logo, pictures, etc.) was stolen by the American company Glassco. After a lengthy lawsuit and losing a case that was almost impossible not to win (due to a mistake of hiring a qualified New York lawyer to fight an away lawsuit in Chicago), Dyson found out - much to his surprise - that the entrepreneurial team had lost all interest in the Ballbarrow and its inventor, and as a consequence Dyson was being ousted from the company he co-founded and partly owned. Furthermore, he (1997: 96) realised that he had assigned the patent for the Ballbarrow to the company rather than to himself: 'I had, in my naked naïveté, assigned the patent for the thing to the company rather than myself. I had no rights at all to the invention I had created and laboured over for so long. It was not a mistake I was ever to make again.' The experience taught him much about the market for consumer goods and the importance of patenting, as well as a third valuable lesson: not go into business with relatives (after he was forced to leave the company he did not speak to his sister or brother for ten years).

Back on his own, James Dyson began working on another one of his ideas, a bag-less vacuum cleaner called the Dual Cyclone (DC), which separated dust without using a filter. Unlike the existing vacuum cleaners, which lost suction as their bags filled up, the DC would not be clogged with dust and thus maintain its suction. It was clear that before the DC could go into production and be sold to a large audience, substantial research and development, 
testing and prototyping, model making and engineering was required. Dyson needed money to develop the new Dyson vacuum cleaner: given the fact that merchant banks were not interested in his business, he fell back on his old friend and mentor Jeremy Fry, who put in $25 \mathrm{k}$, and Dyson put in his own money (initially 25k and another 18k later from selling his garden). Dyson's initial business model was based on selling licenses for the production of the DC to domestic and foreign partners. A good example of a profitable licensing deal was with the North-American company Iona, which in 1992 agreed to sell the Fantom/DC to the consumer market. Dyson's cyclone technology, now added with dry-cleaning facilities, was also licensed to industrial and commercial users in the business-to-business market. This intensive licensing strategy aimed at keeping as many potential licensees in the air as possible meant that Dyson had to invest much of is valuable time and tour the country and the world continuously.

When things turned sour after another major infringement of Dyson's dual cyclone patents by the US company Amway, Dyson (1997: 211) realised that he had to change his business model and decided to manufacture the DC vacuum cleaner completely by himself, supported by an aggressive patent strategy: 'But the forming of the company, and the company name, was crucial. I was about to go up against these big multinationals, and my great advantage, in a jungle ruled by faceless conglomerates, was that I owned this product myself and was personally responsible for everything I sold to my customers, and so I made this clear in the name of both company and product.' After the initial licensing deal with Amway fell through in 1991, the company had clearly appropriated confidential information and damaged the reputation of the Dyson company. The only thing Dyson could do was to sue the Amway corporation for patent infringement. Since most of his revenues went into financing a protracted and extremely expensive legal battle with the US company, rather than 
being available for investment in the development, production and sales of the DC vacuum cleaner, the company regularly faced a shortage of funds and bankruptcy was never far away. After a successful marketing campaign ('Say goodbye to the bag'), positive newspaper reports about the DC vacuum cleaner by enthusiastic journalists who had tried the Dual Cyclone, and the creation of an effective distribution system, sales finally took off. With surging sales and after a legal victory over Amway, Dyson's company started to grow substantially. Initially the DC vacuum cleaner was sold via mail order, followed later by deals with major department stores like Littlewoods, Curry's, Comet and the regional electricity board shops. Dyson's Dual Cyclone was the first vacuum cleaner to be really popular with men: with its almost seethrough plastic, the product had a NASA/space technology touch, and the sight of a transparent vacuum cleaner full of rubbish would draw the eye of the potential customers. From the mid-1990s onwards, the British company started expanding abroad, by investing in commercial relationships with partners in Australia, Japan, France and Germany. The rest is history ... (and goes beyond James Dyson's autobiography).

\section{Networking: looking for and using social capital}

Gabbay \& Leenders (1999: 3) define 'corporate social capital' as 'the set of resources, tangible or virtual, that accrue to a corporate player through the player's social relationships, facilitating the attainment of goals.' The assets from which entrepreneurs or entrepreneurial teams in deal-making and competition are embedded within and made available through social networks, or alternatively the assets entrepreneurs look for to strengthen their strategic position may be found in new social networks and through 'networking'. As a consequence of new legislation or shifts in technology and demand, entrepreneurs may realise that there is a gap between the currently available social capital and 
the social capital required to cope with new demands or opportunities. The response could include a combination of human capital (e.g. more and better education and training of present staff and hiring new employees), financial capital (e.g. negotiating a bank loan or a deal with a venture capitalist) and social capital (e.g. recruiting a new senior manager, approaching new customers, etc.).

Like other forms of capital, social capital is a productive force that makes it possible, for instance, to achieve goals that would otherwise not be attainable. Human, physical and financial capital refers to the possession of knowledge, equipment, and money on the part of an actor or group of actors. Social capital does not reside in a person's skills and diplomas, power over tools and materials, or control over funds, but it is embedded in social ties and networks. Some people argue that social capital can be located in a person's address book, hence the term: Rolodex power. Human, physical and financial capital is different from social capital in at least two ways: in terms of ownership and in terms of contribution to productivity (Burt, 1992). While the former three forms of capital are owned (and to some extent controlled) by individuals, groups or organizations, social capital is owned by the players making up the relationship, with none of them in possession of the exclusive property rights. While the investment of human, physical and human capital will have direct effect on the production capabilities, the availability of social capital is a necessary but not sufficient enabler of growth and innovation. The deployment of social capital will have only an indirect effect on performance, running through the contacts and networks generating the opportunities and the necessary resources. The search for and use of social capital is sometimes the outcome of a deliberate encounter between of an actor and new contacts (e.g. at trade fairs and conferences), but it is often the by-product of other activities (e.g. shared background at high school, work, sport clubs). In fact, actors may not even be aware of the value of their social capital: the social structure in which they are embedded may contain 
information, resources and advantages of which they are unaware (e.g. the children of successful entrepreneurs).

In their work on 'corporate social capital and liability', Leenders \& Gabbay (1999) pay attention to the positive and negative effects of social networks in relation to the realization of goals of small and medium-sized firms and their leaders. Most studies on social networks are extremely positive, arguing that 'networks are good, more networks are better' and supportive social ties help people get jobs, pay rises and faster promotion. Leenders \& Gabbay's book is one is of the few works that offers a balanced approach to the ambiguous effects of social ties and structures: on the one hand they facilitate the search for information, opportunities and resources (i.e. positive social capital), while on the other hand constraining or even impeding the attainment of goals (social liability, also called negative social capital). In this respect, Gargiulo \& Benassi (1999) (included in the Leenders \& Gabbay volume) refer to the bright and dark side of social capital: in the case of a start-up firm, strong ties provided by close relatives, friends and former colleagues could be beneficial at the inception stage (for instance in terms of providing emotional support, money, business recipes), but they could become a liability with regard to future expansion. The company may lack the selfishness, innovativeness and opportunity-seeking focus that is needed at a later stage. For instance, in the case of ethnic entrepreneurship, dense networks can have supporting and yet oppressive effects: ethnic entrepreneurs, who are already short on the vital business contacts outside their local cultural community (e.g. useful weak ties with banks, Chambers of Commerce), may suffocate even more by the particularistic demands posed by the strong ties that have initially provided them with access to essential resources.

The structure of networks may vary from a loose collection of ties to close-knit business groups in which the focal organization is strongly embedded. Granovetter $(1973 ; 1995)$ has specified the intensity and diversity of relationships, i.e. the difference between strong and 
weak ties, on the basis of four criteria: the frequency of contacts, the emotional intensity of the relationship, the degree of intimacy and reciprocal commitments between the actors involved. While weak ties provide access to (new) industry information and to new business contacts, strong tries are relationships that can be relied on at all times. Strong ties tend to bind similar people in longer-term and intense relationships. Affective ties with close friends and relatives may provide a shortcut to or even preclude the search for useful knowledge and access to critical resources. In other words, strong ties contribute to 'economies of time' (Uzzi, 1997: 49): the ability to capitalize quickly on market opportunities. The manifestation of strong ties will also reduce the time spent on monitoring and bargaining over agreements: free-riding behavior will be discouraged and transaction costs reduced. Strong ties are more likely to be useful in situations characterized by high levels of uncertainty and insecurity, e.g. with radical innovations. In such complex settings, individuals rely on close friends and reduction for protection, uncertainty reduction and mutual learning. Krackhardt (1992) has elaborated on the affective component of strong ties by arguing that commitment, loyalty and friendship within an organization will be critical to that organization's ability to deal with major crises. In short, a social structure based on strong ties will promote the development of trust, the transfer of fine-grained information and tacit knowledge, and joint problem-solving (Uzzi, 1997; Rowley et al., 2000).

In situations of high uncertainty, researchers found not only benefits of strong ties, but also limitations. The limitations have to do with the ability to discover information on opportunities to improve the business model of the start-up. In the initial stages, start-ups continuously search for improvements in the way they combine resources in order to satisfy demand in a profitable way. In those situations, weak ties appear to be more beneficial than strong ties when it comes to searching for new information. Burt (1992) elaborates on the strength of weak ties hypothesis (Granovetter 1973; 1995) and argues paradoxically that the 
absence of ties, or more precisely, selective network autonomy (i.e. actors who are connected to disconnected others), may even provide an advantage. In Burt's social network theory, a large diverse network is the best guarantee of having a contact present where useful information is aired. The availability of so-called structural holes in a social network generates an even better pay-off: a structural hole is a relationship of non-redundancy between two contacts (redundant: leading to the same people and thus providing the same information benefits) (Burt, 1992). Burt's advice to improve one's capital is crystal clear: players should invest in non-redundant ties and disinvest redundant relationships.

The weak versus strong tie discussion refers to relational embeddedness. In existing literature, a distinction is drawn between relational and structural embeddedness. Relational embeddedness refers to the characteristics of the relationships, such as strength and content: e.g. strong or weak ties. Structural embeddedness has to do with the structure of a network, or more in particular the position of the firm (or person) within the network structure. The characteristics of the network structure have been described as being either dense or sparse, while the 'structural' position of a firm or person within a network has been described by referring to, for example, centrality or a position rich in structural holes (i.e. allowing for arbitrage and strategic advantage seeking). Although both relational and structural embeddedness may affect firm performance, within both dimensions research has thus far remained inconclusive. In the next section, we look at the various studies and their findings concerning the beneficial effects of particular network characteristics. In any case, empirical evidence suggests that strong ties are beneficial to a firm's performance (including the degree of innovativeness), while in some cases weak ties also appear to be very important. Similarly, some researchers argue in favour of dense networks, while others favour sparse networks. In addition, centrality has great intuitive appeal as being favourable to innovation; in the last decade, however, the concept of structural holes has drawn most attention in relation to the 
discovery of new information and knowledge. Since new information and the ability to find new knowledge appear to be crucial to innovation, the structural hole argument has great potential, which is why we discuss it in greater detail.

The structural hole argument has to do with information advantages that benefit people who build across cohesive groups, exploiting a position on the intersection between two groups. In addition to benefiting from brokering the flow of information between people, structural holes also allow entrepreneurs to benefit from the subtle control of projects that bring together people who are not (yet) connected. In the structural holes theory, three concepts are play a central role: brokerage, entrepreneurship and structural holes. Brokerage includes an early and efficient access to valuable information and referrals to new contacts. According to Burt (1992: 34), an entrepreneur is 'a person who generates profit from being between others'. Eventually, being close to the social holes and benefiting from them through arbitrage pays off (Burt, 1992): it implies being exposed to diverse sources of information and subsequently having a better chance to gain access good ideas. Also, firms with a more heterogeneous mix of alliance partners enjoy faster revenue growth and tend to obtain more obtaining patents; similarly, managers with a network that has been optimized for structural holes were rewarded with better compensation, performance evaluations and faster promotions.

\section{Innovation and knowledge brokering}

Innovation can be described as the discovery of new ideas and concepts, new combinations and new organizational approaches, often resulting in new products or processes and sometimes to the formation of new ventures. Innovation is often portrayed as an iterative, cumulative and interactive process, involving all kinds of learning: learning by doing, learning 
by using and learning by interacting (Quinn et al., 1997; March, 1991). Elaborating on Schumpeter's notions of creative destruction and new combinations, Weick (1979: 252-253) has defined creativity as 'putting old things into new combinations and new things into old combinations. In either case, novel relations between pairs of things are the essence of creativity.' The process of innovation typically transcends the boundaries of existing firms, industries and populations of organizations.

Knowledge brokering and learning for innovation can be studied at various levels of analysis. Firstly, we take a look at the network level. A key conceptual contribution to this level of analysis is the 'locus of innovation' study by Powell et al. (1996). Hargadon (1997; 1998; 2003) examines a similar issue from the point of view of the individual firm and investigates how knowledge brokering through network ties contributes to the realization of innovations. We first discuss the contribution by Powell and associates, followed by a summary of the findings of the various studies by Hargadon.

In their research into the locus of innovation, Powell et al. (1996) have applied a social network approach to analyze the emergence of collaboration and competition in the biotechnology sector. After drawing a sample of dedicated biotechnology firms in the early nineties, they have mapped out the evolution of the network structures in this emerging industry, and have subsequently examined and explained their effects on organizational learning. With their data on collaborative ties (e.g. R\&D alliances, investment and marketing cooperation) between dedicated biotech firms and their strategic partners (e.g. other dedicated biotech firms, venture capitalists, universities, pharmaceutical firms), Powell et al. have tested several hypotheses concerning the relationships between $R \& D$ alliances, experiences with inter-firm relationship management, network positions, rates of growth and portfolios of collaborative activities. The first hypothesis, which links a firm's current number of R\&D alliances and collaborative experience to future non-R\&D ties and any diversity of ties, is 
confirmed by the data. Similarly, the second hypothesis, which relates the number of R\&D alliances, collaborative experience and portfolio diversity to a firm's centrality within a network in the subsequent year, is supported. All three variables have a positive influence on how fast and deep a firm becomes centrally connected in the inter-firm network. The third hypothesis, stipulating that collaborative experience and network centrality have a positive impact on a firm's growth (operationalized in terms of number of employees and stock market performance) is strongly supported by the results. Finally, the fourth hypothesis, predicting that centrality positively affects future collaborative R\&D activity, was also confirmed by the data; i.e. occupying a central position in a network implies that a firm has relatively more opportunities for future collaboration.

The central thesis emerging from the empirical findings of Powell et al. (1996) is that, in many of the high-technology industries, today's networks of inter-firm collaboration are characterized by cycles of mutual learning. A market entry through R\&D partnerships offers young biotechnology firms pathways to access information and ideas as well as opportunities for further collaboration in other areas, which provide additional possibilities to collect and incorporate new knowledge. Collaboration allows the firms to carry out R\&D and develop new alternatives, while simultaneously mitigating the costs, risks and problems associated with such an exploration route. An early choice in favour of exploration through collaboration will generate positive feedback firms can also use to enhance their exploitation efforts and refine and extend their existing competencies (March, 1991). The development of experience and diversity in network ties not only infuses the dedicated biotechnology firms with experiences with managing inter-firm linkages, but external collaboration also helps develop and strengthen internal competencies for evaluating external research and appropriating the new information and resources. In other words, when they exchange, share and assimilate expertise and experience, these biotechnology firms continuously enhance their 'absorptive 
capacity' (Cohen \& Levinthal, 1990). In this respect, inter-firm collaboration (and its offspring) is neither a substitute for internal $R \& D$, nor compensation for internal capabilities that are lacking, but external collaboration, as Powell et al. (1996) emphasize, allows firms to enhance all of their competencies.

According to Hargadon $(1997 ; 1998 ; 2003)$, the area of innovation theory and management contains a few persistent myths, such as the cult of the lone creative inventor, the instantaneity of the invention, the creation of everything from nothing, the clear break from the past and the linearity of the invention into a marketable product. In today's world, there are, however, no solitary geniuses, no immaculate innovations, no glorious Eureka moments. The idea that new inventions are built from scratch and the assumption that the development between idea and marketable product is a linear process are also myths. The 'new new thing', regarded as something to be developed to aspire for the future, is often a recombination of existing components in a process that involves adopting and adapting solutions. There is no such thing as an 'immaculate innovation', born of sheer inspiration and untouched by previous inventions, created by extraordinary people in a flash of genius. Instead, innovators like Thomas Edison or James Dyson put inventions together from what they already know and recombine existing ideas and practices from other industries and innovators. Innovation requires various kinds of input, skills and combinative capabilities. Edison, for instance, did not owe his success to his ability to build something from nothing, but rather to his ability to exploit his network, and borrow the ideas of others and incorporate and recombine them in his breakthrough innovations. Edison was not a lone creative genius, but he depended on the close collaboration of his team in his own lab, and extraordinary innovations are often the result of recombinant invention, and innovation is the result of synthesizing and bridging ideas from different domains. Most of Edison's innovations were improvements on existing 
products and he drew on existing ideas of other people while working on similar problems in other industries.

The pursuit of innovation, however, involves bringing together previously disparate people, ideas and objects, and inventions emerge in the interactions of the groups involved. As Hargadon (2003) argues convincingly, there is an inherent paradox in the innovation process: on the one hand, innovators need wide-ranging ties from distant environments to generate the sketchy innovative ideas, while, on the other hand, they also need the backing of solid and determined partners and mobilize support for their emerging innovations. In the words of Hargadon (2003: 17): 'What set Edison's laboratory apart was not the ability to shut itself of from the rest of the world, to create something from nothing, to think outside the box. Exactly the opposite: It was the ability to connect that made the lab so innovative. If Edison ignored anything, it was the belief that innovation was about the solitary pursuit of invention. Edison was able to continuously innovate because he knew how to exploit the networked landscape of his time.' Edison is a broker par excellence: well-positioned between two otherwise disconnected groups, the broker seeks to combine existing but previously distant objects, ideas and people in new ways, building new networks between and around these innovative (re)combinations. For Hargadon (2003), technology or knowledge brokering includes both bridging old and small worlds effectively and building new worlds from the best pieces of the old ones. These knowledge brokers have access to a broader range of ideas and span multiple industries and technology domains and innovate by putting the various ingredients together into a new solution.

Hargadon \& Sutton (1997) have looked at the importance of brokering in product design companies, such as IDEO and Design Continuum. These 'invention factories' seek to create and make both technically feasible and commercially viable innovations for their customers. Their business is 'innovation on demand' and in order to make these new products, 
concepts and solutions, little creativity is needed. Like Edison's laboratory of the past, these product design companies act as brokers, capitalizing successfully on their connections with many different industries that may not otherwise be connected. As true (technology) brokers, they clearly benefit from their central position and from gaps in the information flow between subgroups in a larger network, and they fill these gaps by combining technologies from within and outside their client's industry into new solutions. They bring together information flows and design solutions in one area that are potentially valuable in others. Technology brokering furthermore depends on organizational memory, which allows a company to acquire, retain and retrieve new combinations of information for possible use in future design projects. The process of technology brokering is visible not only at the intermediate level (between firms and between sectors), but also at the micro-level (among professionals, teams and divisions). Within firms, product developers and designers see each other and their larger community as a valuable clearinghouse for generating and selecting solutions, drawing upon the ideas, tools and artefacts of themselves, their colleagues and the joint input and feedback at Monday morning meetings and informal lunches. Thus, networks appear to be crucial to knowledge brokering. New combinations, an important form of innovation, often involve a combination of outside knowledge with inside competences, which means that the brokering role provided by network ties play a pivotal role in innovations. Consequently, in the next section we focus on the network contribution to innovation.

\section{Networks and innovation}

In innovative entrepreneurship literature, there is a clear bias in favour of heroic entrepreneurs breaking away from existing practices and introducing radically new products and services. This picture does not apply to most entrepreneurs, however, because to a large extent they 
maintain the status quo by imitating established ideas and practices and/or marketing incremental innovations. Relevant earlier experience is a crucial variable in this respect: actors with extensive experience in an industry are less likely to be innovative than those with limited experience. Unfamiliarity with or even indifference to industry routines and norms may allow outsiders to break away from the cognitive and institutional constraints facing incumbents. Another myth is that these heroic entrepreneurs predominantly act individually and selfishly. Most entrepreneurial activities, even those of solo entrepreneurs, are embedded in ongoing networks of social relationships (Granovetter, 1985). Uzzi (1997) argues that the social and economic embeddedness of entrepreneurs is a two-edged sword, ranging from under-embedded (dominated by strong profit orientation, individualism and arm's length relationships) to over-embedded networks (characterized by knowledge-sharing and trustbased relationships).

Young entrepreneurial ventures often lack the resources that are needed to survive and grow. This 'liability of newness' (Stinchcombe, 1965) results from the high levels of uncertainty and vulnerability surrounding new ventures and their future prospects, which make potential resource providers hesitant to commit resources to start-up firms. In addressing the question as to how new ventures can overcome the problems associated with low levels of legitimacy, Stuart et al. (1999) suggest that inter-organizational exchange relationships can act as endorsements that influence the perceived quality of young organizations when other indicators are unavailable. Inter-organizational collaboration can also be a locus for innovation (Powell et al., 1996). Rather than obtaining new information through the market place (e.g. buying information, hiring consultants, etc.) or organizing the innovation process internally through the corporate hierarchy (e.g. indigenous R\&D departments), the source of new information and ideas in knowledge-intensive industries is explored and exploited collectively by inter-firm partnerships and mutual learning. In the 
biotechnology sector, for instance, a complex and rapidly expanding sector that is characterized by a widely dispersed knowledge base, collaboration stems from the actors' need to explore new fields and gain access to specific knowledge and resources. At a later stage, after having learned the tricks and the trade of inter-organizational collaboration and learning with various partners, they can widen and deepen their competencies and knowledge base (and possibly develop new products).

The search process in which entrepreneurs engage to find information, resources and partners within their industrial community consists of a matching process in which participants use a combined set of categories to identify a set of potential participants and relational criteria to establish the trustworthiness of the participants, using emotional criteria, as generated in face-to-face interactions, to decide whether they should further pursue a relationship (Nohria 1992). One entrepreneur sees new venture creation, like innovation, as a case of brokering: 'a high-technology venture is like a jigsaw puzzle. Each of the pieces is unique and must fit together perfectly if you want the venture to be a success. So the chase in which everybody is involved - be it the entrepreneur, the venture capitalist, the management candidate or whoever else is in the game - is the search for those perfect 'matches' that will help put the puzzle together (in Nohria 1992: 243).'

\section{The importance of weak external ties and structural holes}

New technology firms are extremely risky, as they pursue to commercialize unproven technologies that require substantial investments while future revenues are highly uncertain. Since the quality of these ventures often cannot be observed directly, for example from a proven patenting track record, resource holders must assess the value of a young company by looking at the attributes of its exchange partners. There are three mechanisms that explain 
why the social structure of business relationships can significantly affect the perceptions of the quality (and hence value) of new ventures: reciprocal relationships, quality assessments and reliability. In their study involving a sample of 301 young biotechnology firms, Stuart et al. (1999) demonstrate that the prominence of the exchange partners of these firms has a significant positive impact on their subsequent performance.

The first mechanism affecting the perceived quality of a new venture quality are affected stresses the reciprocal nature of exchange relationships. Because ties have a reciprocal impact on the reputation of actors, reputable actors run the risk of damaging their reputation when engaging in relationships with low quality ventures. The second mechanism involves the ability of reputable actors to make valid assessments in conditions of high uncertainty. Prominent third parties are assumed to have superior expertise at the due diligence process, which implies that a decision to transact with a new venture reflects an endorsement of sufficient quality with regard to the start-up organization. The third mechanism through which third party affiliations influence the perceived quality of new ventures concerns the signalling effect of these affiliations. Assuming that reputable partners will eschew relationships with low quality ventures and that entering into a relationship with reputable partners draws relatively more attention to a new venture, these exchange relationships signal the reliability and trustworthiness of the young firm to a wide audience.

The empirical analysis focuses on three types of inter-firm collaborations: $R \& D$ alliances, marketing alliances, and product development alliances. Hypotheses are tested that relate the prominence of strategic alliance partners, outside investors and the investment bank of young companies to higher performance in terms of time-to-IPO and market value at the time of an initial public offering (IPO) (investment bank prominence is measured by taking a prestige ranking for the banks concerned). The prominence of alliance partners and outside investors is measured in terms of their commercial and technological stature. The former 
refers to actor centrality in the strategic alliance network, while the latter involves the centrality score of the affiliation partner in the biotechnology patent citation network, which consists of all patent citations among biotech firms.

Controlling for firm differences and environmental conditions, the empirical analyses show that new firms with prominent exchange partners go public faster and receive significantly higher valuations when they do. That this is especially true for new firms about which there was high uncertainty is an indication that the positive effects of these affiliations is not only due to access to valuable resources, but also to a transfer of status from prominent partners to new firms. Further analyses indicate that ventures that exchange with prominent partners are able to do so across all types of alliances, which indicates that the endorsements involved have a positive impact on future opportunities to collaborate with prominent partners.

The central question posed by Ruef (2002) has to do with the factors that enable or constrain entrepreneurs (or entrepreneurial teams) to engage in creative action, measured by the number of patent and trademark applications and subjective perceptions about innovations by the entrepreneurs themselves. Ruef (2002) investigates the impact of the social networks of entrepreneurs on their creative actions. These social relationships, including external contacts (e.g. with investors, customers, knowledge centres, etc.) and internal ties (e.g. composition of teams, the structure and the nature of intrafirm networks), can have both a positive and negative effect on innovativeness. In Ruef's theoretical framework, the capacity for creative action is seen as a function of three underlying structural and cultural mechanisms: (1) accessing diverse sources of information and obtain non-redundant information from social networks; (ii) avoiding pressures to conform; and (iii) to sustain trust with others who are told about a potential innovation in developing new- and potentially profitable - innovations. The 
intensity, content and diversity of the social ties is specified and operationalised in the following ways:

- strong ties: discussions with relatives and friends;

- weak ties: discussions with business associates, such as customers and suppliers;

- ties directed towards discourse: discussions in the general media or specialized press. ${ }^{2}$

Using a sample of 766 single and multimember teams that all attempted to start business ventures, Ruef examined how the social network ties and enculturation of entrepreneurs affect their level of innovative activity. His empirical results provide strong support for the expectation that entrepreneurs relying on weak ties (acquaintances) as sources of ideas are more innovative than those with strong ties (family and friends), since weak ties offer new information (echoing Granovetter, 1973; 1995) and present less pressure for social conformity. His results also demonstrate the value of network diversity. Entrepreneurs with heterogeneous networks are significantly more likely to engage in innovative behaviour than those with homogenous networks. This suggests that diversity combines the feedback benefits of social ties with the lack of pressure to conform associated with directed ties. Next, entrepreneurs with ties that are directed at the concrete activities of other actors are found to be more innovative and those with ties directed to the abstract discussion of ideas in expert discourse (e.g. the business press) to be less innovative than entrepreneurs relying on weak ties. This is explained by the notion that the former present ready-to-implement solutions, while the latter only offer general ideas that require adaptation to the specific context, thereby fostering creativity and innovation.

Because many ventures are set up by entrepreneurial teams, Ruef has looked into the role of team structure and internal ties. He found that team size and role diversity among team

\footnotetext{
2 One could add a fourth category, namely market-based ties, that includes the hiring of incidental and irregular assistance to solve operational or financial bottlenecks in the organization (e.g. through consultants). From the distinction among several ties made and discussed above, its is not clear into which category internal colleagues fall: some close colleagues provide strong ties, while others from different teams can be seen as weak ties, and in some cases these internal ties may become almost vertical lines of authority.
} 
members had a positive affect on innovation efforts, but when limiting the sample to team start-ups, these variables were insignificant, which indicates that teams are more innovative than solo entrepreneurs, as they tap into a larger and more diverse pool of knowledge, but that this benefit only occurs when moving from single to multimember teams. Similarly, role diversity may only be beneficial when performed by solo entrepreneurs, but not for heterogeneous teams. Next, teams composed exclusively of relatives, friends or work colleagues (strong ties) were found to be slightly less innovative than those consisting of acquaintances or a mix of relatives, friends and colleagues (weak ties), who in turn were slightly less innovative than teams involving no prior relationships. The differences were, however, not statistically significant, which may be explained by the possibility that, once teams are formed that involve people without prior relationships, cohesion among group members builds quickly and weak ties become stronger.

In addition to the entrepreneurs' structural embeddedness in social networks, Ruef (2002) also investigates the effect of the cultural embeddedness of entrepreneurs on their innovative behaviour. Cultural embeddedness refers to the level of experience an actor has in a particular task domain, the extent to which that experience is used and the degree to which it involves conventional routines and competences. Entrepreneurs with extensive experience in the industry in which their new venture operates may be less likely to depart from the norms and routines that are prevalent in that industry. Controlling for the age of entrepreneurs, the empirical analyses show that both in the whole sample and in the sub-sample of multimember teams, the (average) number of years of industry experience significantly decreases the likelihood that entrepreneurs perceive themselves as innovators and that they apply for patents or trademarks.

The overall development of more diverse network ties, higher levels of absorptive capacity and better internal capabilities allows firms to increase their centrality in the 
collaboration network. This inter-organizational network, however, also reflects the nature and intensity of competition in a given sector. The strategic positioning, manoeuvring and partnering of these firms in the biotechnology not only shape their reputation and status among peers, but the degree of connectedness may provide a lever to access more and better knowledge and attract additional partners. This enhanced centrality and visibility as a respectable partner implies access to the core of the network in terms of better access to critical resources and information on emerging opportunities. A dynamic feedback process involving organizational learning is set in motion, in which centrally positioned firms are provided with better opportunities and better strategic partners to further and benefit from R\&D, overall collaboration, additional ideas and knowledge, and spill-overs in other areas. Alternatively, firms with a less central position in the network or without collaborative relationships face a so-called 'liability of unconnectedness', which inhibits access to valuable knowledge and strategic partners (Powell et al. 1996: 143).

\section{The importance of strong external ties}

Entrepreneurs try to compensate a shortage of human and financial capital by resorting to their networks. Close support networks, based on strong ties (e.g. spouse, family) may provide a founder/owner with the resources he or she is lacking (Brüderl \& Preisendörfer 1998). Although founders with a broad network may simply have more opportunities to raise start-up capital, active help from spouse of life partner and particular support from the family network are vital to increase the chances of success and provide stability to the new firm in its early stages. Yli-Renko et al. (2001) have examined how the social capital embedded in relationships between young technology-based firms and their single largest customer affects knowledge acquisition and how this knowledge mediates the relationship between social 
capital and knowledge exploitation for competitive advantage. Using a sample of 180 young technology-based firms in the U.K., the first set of hypotheses relates three aspects of social capital (social interaction, relationship quality, and customer network ties) embedded in the firms' relationships with their key customer (highest proportion of sales revenue) to the acquisition of external business knowledge. A second set of hypotheses examines how this knowledge acquisition relates to knowledge exploitation in terms of new product development, enhanced technological distinctiveness and reductions in sales costs.

The empirical findings of the above-mentioned study support the prediction that social interaction and customer network ties significantly increase knowledge acquisition by new technology-based firms, while, in contrast to expectations, the quality of the relationships was found to have a significant negative effect on knowledge acquisition. Higher levels of social interaction that involve intensive and frequent interactions increase knowledge acquisition by means of a more intense information exchange, an increased willingness and ability to share knowledge and a better ability on the part of firms to recognize and evaluate knowledge. Customer network ties, which refers to the ability of a key customer to provide the focal firm with introductions to a broader set of customers, enhances knowledge acquisition, as it offers technology-based firms access to a wider pool of knowledge embedded in indirect ties, making it possible to build knowledge integration skills. Finally, the finding that the quality of relationships decreases knowledge acquisition may be explained by the possibility that, although it may lower monitoring costs and speed up exchange processes, it does not increase the amount of external knowledge acquisition.

After having looked at the relationship between social capital, i.e. the linkages of young technology-based firms with their key customers and knowledge acquisition, Yli-Renko et al. (2001) analyze how this knowledge acquisition relates to knowledge exploitation aimed at gaining a competitive advantage. They find that knowledge acquisition, measured by four 
statements asking respondents to what extent they obtain business knowledge from their key customer, has a significant positive relationship with the number of new product introductions and the technological distinctiveness of young technology-based firms. The former is measured by estimates regarding new products resulting specifically from the key customer relationship, while the latter is measured by three statements regarding the extent to which the firm's technology is a source of competitive advantage. Interestingly, the observation that key customer ties improve a firm's technological distinctiveness is at odds with other studies arguing that relying too much on a single customer may reduce the creativity and innovation of young ventures. Finally, the results demonstrate that knowledge acquisition has a significant negative relationship to the sales cost levels of young technology-based firms. This indicates that knowledge acquired from key customers allows these firms to improve the efficiency of their overall operations. Knowledge gained from a specific collaboration is consequently applied effectively in other areas to raise the firms' effectiveness in a variety of domains.

In contrast to many other studies that explain differences in capabilities among firms by taking an atomistic view in which firms are assumed to act alone and produce their capabilities internally, McEvily \& Zaheer (1999) take an embeddedness-oriented perspective by looking at the external sources of competencies. They try to explain the heterogeneity in a firm's capabilities by referring to the differences in its network ties. Using a stratified random sample of 227 manufacturers located in the Midwest of the United States, the study specifically tests hypotheses regarding the relationship between bridging ties, participation in regional institutions and the acquisition of competitive capabilities by firms operating within the same geographical cluster. It is expected that firms located in these clusters benefit from the high levels of trust embedded in those tight-knit communities, as well as from the knowledge-sharing that enhances organizational learning by providing access to new 
information. Since firms maintain idiosyncratic patterns of social network ties, they may be differentially exposed to new information and opportunities arising in these clusters. Bridging ties refer to relationships that link a focal firm to contacts in economic, professional, and social circles that are not otherwise accessible to the firm.

To test these alternative explanations, McKevily \& Zaheer (1999) relate structural holes (Burt) and tie strength (Granovetter) measures in a firm's advice networks (the five most important sources of advice) to the acquisition of three competitive capabilities that are specific to the job shop manufacturing industry: pollution prevention, quality management and competitive scanning. Controlling for firm size and age, the hypothesis that structural holes in the advice network (measured in terms of its density) have a positive effect on the acquisition of capabilities is strongly supported. By contrast, weak ties, operationalised in terms of infrequency of interaction with the advice network and the geographic dispersion of these contacts, turn out to be insignificantly related to the acquisition of capabilities. Although geographic dispersion is significantly related to one of the three capabilities, the general results confirm the argument that non-redundant networks leverage organizational performance. In addition to bridging ties, the acquisition of competitive capabilities may also be enhanced by ties to regional support institutions. Given the intermediary role of these institutions within networks, they facilitate access to a varied pool of information and knowledge at low cost to participating firms. This access allows member firms to acquire new capabilities and extend existing ones,. A three-item scale capturing the use of available services measured participation in regional institutions. The findings of McKevily \& Zaheer (1999) to a large extent confirm the hypothesis that ties to regional institutions enhance capability acquisition. In addition, empirical evidence supports the expectation that structural holes in a firm's advice network are negatively related to participation in regional institutions. This suggests that firms with networks that are rich in information are aware of their value 
and are consequently hesitant to engage in regional institutions, as this may involve the risk of proprietary information leaking to other firms in the cluster.

\section{The contingency argument to reconcile conflicting results}

The contingency argument supposes that the need to innovate and engage in networking activities varies across sectors and depends on the ambitions, experience and tasks of the entrepreneur, and the phase in which where his company and industry finds itself. In stable and well-organised sectors, the networking activities of owner-entrepreneurs aimed at collecting information and mobilize resources seem to be limited (Chell \& Baines, 2000; O'Donnell, 2004). This may be due to the fact that those owner-entrepreneurs may not have a strong need to search for new knowledge through old and new, and strong and weak ties (the overall level of innovativeness and competition are not that high). They may also be inwardlooking and prefer to run their firm as their empire (the corporation as a fortress) almost by themselves, and they may not have the time or social skills needed for strategic networking. Chell \& Baines (2000) have emphasised that it is especially in knowledge-intensive industries that most entrepreneurs force themselves (or are forced by others) to be pro-active and to invest time and energy in their networking in order to grow. The ambition to innovate and grow is then materialized through the active pursuit of new opportunities and the mobilization of additional valuable resources through network contacts, in many cases more specifically through external and weak network ties. Chell \& Baines (2000) have also tried to analyze the role of social networks at critical junctures in the career path of owner-founders or the life cycle of their companies. In the case of so-called critical incidents in the personal development of entrepreneurs and in the evolution of their firms, social networks are important and they are functional in the sense that they put entrepreneurs and their firm back 
on track. Unfortunately, Chell \& Baines are unable to specify whether at such a turning point in either a person's or a firm's development, strong or weak ties, and internal or external networks are relevant and decisive.

Another contingency is time or, more particularly, the phase of growth of a start-up. On the basis of a literature review, Hite and Hesterly (2001) argue that, in the emergence phase, start-up firms benefit most from strong ties. In that phase, they need a 'friend's favour' in terms of being provided with access to resources. The advantages of weak ties and structural holes only become relevant later on in the early growth stage, when start-ups have to explore new markets or products and expand their network to include weak ties as well. The argument involving the dependence on strong ties has to do with the high level of uncertainty with which the new venture is faced. Strong ties are willing to provide the resources despite the uncertainty, while weak ties tend not to take the risk associated with the uncertain future of a start-up.

Furthermore, in the early growth phase, it is necessary to develop a more diverse network in which weak ties may appear to be crucial in terms of discovering structural holes, which are important in gaining access to new resource providers to fuel further growth. Thus, Hite \& Hesterly (2001) propose that network benefits develop from the exploitation of strong ties to the exploration of weak ties. The argument by Hite \& Hesterly (2001) concerning the growing importance of weak ties as a venture evolves from emergence to early growth emphasizes the need to find structural holes. Structural holes and the role of weak ties are related to the discovery of information about new growth areas. This information, and consequently weak ties, may be important in terms of spotting new opportunities. Of course this search process will benefit from weak ties, but it remains to be seen whether the weak tie benefit is not much larger in the emergence phase (Elfring \& Hulsink, 2007). In that phase, when the entrepreneur, the firm and the portfolio of activities have not yet been proven and 
lack a track record, there is a great need for information and advice about the products and the business model to be selected.

Rowley, Behrens \& Krackhardt (2000) also adopt a contingency-oriented perspective to explore the conditions under which sparse (or dense) and strong (or weak) ties are positively related to firm performance, by specifying a particular industry context. They expect that the relationship between embeddedness and firm performance is moderated by the uncertainty and level of innovation in the environment: 'strong and weak ties are beneficial to firms but under different conditions for different purposes and at different times (Rowley, Behrens \& Krackhardt 2000: 383).' In their study on inter-firm collaboration and its influence on performance, Rowley et al. (2000) address the question as to how firms are embedded in networks of alliances in their particular industry, in this case the dynamic and innovative semiconductor industry or the relatively stable and well-organised steel sector.

Furthermore, they investigate structural and relational embeddedness at the same time, basically to show that these are no independent constructs, but that the interaction between them is an important variable. Relational embeddedness refers to the strength of relationships and the assets rooted in these ties. Strong ties are argued to provide trust-based governance and fine-grained information transfer due to a frequent interaction between relatively similar actors. Weak ties, on the other hand, provide access to new information, as they usually connect actors with different backgrounds. Structural embeddedness concerns the pattern of relationships and the presence or absence of ties between pairs of actors. Sparse networks rich in structural holes between disconnected actors are argued to enhance access to new information, while cohesive networks with high levels of interconnectedness are expected to encourage cooperative behaviour between actors in the network.

Drawing on two datasets involving horizontal strategic alliances in the semiconductor and steel industries, hypotheses are tested regarding the effects of relational and structural 
embeddedness, as well as the interaction between the two, on firm performance in both industries. Data is collected for the period 1990-1997 and collaboration is categorized as either consisting of weak ties, operationalised as alliances involving technology licensing or marketing agreements, or of strong ties that involve non-equity R\&D collaboration, joint ventures or equity alliances. The empirical findings confirm the hypotheses that weak tie collaboration has a significant positive relationship with firm performance (return on assets) in the semiconductor industry, whereas strong ties significantly increase the performance of collaborators in the steel industry. However, the hypothesis that strong ties have a significant negative relationship to firm performance in the semiconductor industry is not supported. These findings indicate that in environments that are characterized by high degrees of uncertainty and that demand more exploration on the part of firms, weak ties are more valuable due to their informational advantages. Empirical evidence with regard to the value of networks that are rich in structural holes vis-à-vis network cohesion suggests that industry context again plays an important role. A significant positive relationship between firm performance and network density is found in the steel industry, which suggests that firms in environments that characterized by high degree of stability and exploitation benefit more from dense networks.

On the basis of the independent tests of relational and structural embeddedness on firm performance in both industries, Rowley, Behrens and Krackhardt (2000) argue that strong ties and dense networks provide firms with alternative governance mechanisms, which when combined provide little additional benefit. To test this hypothesis, an interaction variable is introduced to the model that captures the relationships between the two constructs. The findings indeed confirm the prediction that maintaining strong ties when a firm's contacts are already highly connected has a significant negative relationship $(\mathrm{p}<0.10)$ with firm performance, both in the combined sample and in the two separate samples. This suggests that 
the roles that interconnectedness and tie strength play in firm performance are highly interdependent.

\section{Combining strong/weak tie contributions and/or internal/external network sources}

In his longitudinal study on the emergence of inter-organizational alliances of learning in the international chemicals industry, Ahuja (2000) relates three different aspects of a firm's network of horizontal technological alliances to the firm's subsequent innovation output, as measured in terms of the number of patents in a given year: direct ties (access to resource and information), indirect ties (sources of information) and structural holes (disconnections between a firm's partners may expand the diversity of information). Ahuja (2000) mentions two primary benefits of inter-firm technological collaboration: resource sharing (sharing tacit knowledge, skills and physical assets) and knowledge spillovers (transmission of codified information in terms of news about technological breakthroughs, new insights into problems or failed approaches).

Three dimensions of a firm's alliance network that are important drivers of innovation are the number of direct ties, the number of indirect ties and the number of structural holes. First, the number of direct ties can have a positive impact on innovative output by providing firms with enhanced knowledge-sharing abilities, complementary skills and assets from different firms, and economies of scale, since larger projects significantly generate more knowledge than smaller projects. Next, a firm's innovative output may not only be stimulated by benefits provided through their direct partners, but also be increased by the knowledge spillovers from their partners' partners. These indirect ties increase the amount of new information received by firms on promising new opportunities and enhance their ability to identify partners that have valuable information concerning specific problem areas. Finally, 
structural holes may both increase and reduce a firm's innovative output. From a knowledge spillover point of view, structural holes increase access to non-redundant information. From a resource sharing perspective, structural holes imply a lack of trust-building and a risk of opportunistic behaviour that inhibit cooperation and resource-sharing.

The hypotheses are tested on a longitudinal dataset comprising the linkage and patenting activities of 97 leading firms from the chemicals industry in Western Europe, Japan and the United States between 1981 and 1991. Control variables include a firm's R\&D expenditures, size, diversification of sales, strategic focus, international research presence, profitability and liquidity, and the technological distance between the firm and its partners. Empirical results confirm the predictions that the number of direct and indirect ties has a significant positive relationship to innovation output. Furthermore, introducing an interaction variable reveals that the value of indirect ties is inversely related to a firm's number of direct ties. Finally, the number of structural holes is found to have a significant negative relationship to innovation output.

The finding that indirect ties have a positive impact on innovation suggests that these ties provide firms with a mechanism of knowledge spillovers that contributes to innovation. Given the low costs of maintaining indirect ties, it may therefore seem optimal for firms to build large networks of indirect ties. However, three factors need to be considered before doing so. First of all, the benefits of direct ties (resource-sharing and knowledge spillover) are different than those provided by indirect ties (knowledge spillovers only). The degree to which substitution is possible is therefore limited. Secondly, even when the kind of benefits that are being provided are the same, their magnitude may vary significantly between the two types of ties. The benefits of direct ties are significantly larger than those provided by indirect ties, as the latter often also involve competitors that may appropriate the same benefits. Thirdly, having a large number of direct ties may involve a limited ability on the part of a firm 
to benefit from information provided by its indirect ties, since the information that is being exchanged also reaches the firm's direct ties.

Recently, Burt (2000) has contributed to the debate on the (beneficial or detrimental) effects of a dense network with trust and strong ties (Krackhardt, 1992; Coleman, 1998) versus a sparse network with few redundancies and weak ties (Granovetter, 1973; 1995; Burt, 1992) on the performance of entrepreneurial ventures. Alternatively, cohesive networks act as a defence against opportunism and structural holes/weak tie networks help prevent lock-in, conservatism and rigidity. While structural holes theory offers firms informational and control advantages (diversity, strategic positioning), network closure theory highlights benefits in exchanging trustworthy information and tacit knowledge, joint problem solving and collective monitoring. Burt (2000: 410) tries to reconcile the two perspectives: 'although brokerage across structural holes is the source of added value, closure can be critical to realising the value buried in the holes.' Although structural holes may provide an entrepreneur or manager with timely access to and information about new opportunities, cohesive ties among players whose cooperation is also needed in order to exploit those opportunities is also an essential component of success. To find a balance between safety and adaptability (both bonding and bridging are needed to generate and sustain innovation), a mixture of a union and disunion strategy is required, depending on the institutional context and the stage of the industry's life cycle (Baker \& Obstfeld, 1999).

An attempt to look at bridging the contribution of internal and external networks to firm performance was made by Menon \& Pfeffer (2003), who try to analyze the ways in which managers value knowledge from internal and external sources. While most theories take favouritism towards insiders into account, Menon \& Pfeffer (2003) found that a preference in favour of knowledge obtained from outsiders was also prevalent. In some situations, managers may prefer internal knowledge, because they tend to overemphasize readily available 
knowledge and can limit their search to internally available or do-able options; in existing literature, this is described by concepts like as in-group favouritism, the 'not-invented here' syndrome, and out-group derogation. Menon \& Pfeffer have demonstrated that managers value external knowledge more highly than internal knowledge. In fact, the companies in their small sample were almost unresponsive to internal knowledge, while being receptive when it came to ideas and technologies that originated their company (the 'invented-elsewhere' syndrome, exhibiting a favouritism to out-group knowledge and overemphasizing the importance of external knowledge (in-group denigration)).

Thus, less accessible and sparser external knowledge became relatively overvalued and overused, compared to accessible rich internal knowledge, from which value could have been captured more easily. Menon \& Pfeffer try to explain this preference for outsider knowledge by referring to the contrasting status implications of learning from internal versus external competitors and to the relative availability of knowledge (internal knowledge is readily available but subject to greater scrutiny, while external knowledge is more special and unique despite being sparse). In short, strong market competition seemed to make knowledge from external sources more valuable for managers than ideas and information that is generated internally, and when the external knowledge was internalised, the managers saw it as less valuable. In table 5.1, an overview is provided of the key research publications in the domain of social networks and innovativeness by (small and young) firms.

Table 5.1 Overview of selected studies

$<$ Table 5.1 here $>$ 


\section{Conclusion}

External network ties, in combination with internal competences, play an important role in the discovery and realization of innovations. However, it is not true that more ties or larger networks are by definition better. A particular mix of strong and weak ties and a particular position in the network structure is preferable when it comes to discovering and realizing innovations. James Dyson, for instance, needed attorneys to defend himself against the two major companies infringing upon his intellectual property rights (Glassco in the case of with the Ballbarrow in the 1980s and Amway with the dual cyclone technology in the 1990s). While in the former case he hired a prestigious law firm from New York that had to play a less interesting and difficult to win out-of-town game and lost, almost a decade lused a local attorney for his second far bigger lawsuit in the USA: 'Having learnt from the Ballbarrow case that out of town lawyers rarely triumph in America, we hired a lawyer from the town where the case was being heard' (Dyson 1997: 180). The importance of using a local contact paid off and Dyson won. Much of the debate on the importance of social networking for innovation for (young and small) firms has to do with the question which ties matter when. The central aim of this chapter has been to review existing literature on the various dimensions of networks and examine how these different network dimensions may contribute to innovation. Although we can draw some conclusions about particular network benefits, many issues about the most 'optimal' network with regard to innovation remain unresolved. Contingencies play an important role, and most researchers have agreed that the purpose and circumstances have a major impact on the particular role network ties can play.

Table 5.2 Contingencies and network benefits to innovation

<Table 5.2 here> 
What do we know? The higher the level of uncertainty and the greater the need to search for the exact nature of an innovation the more important new information is. Thus, weak ties and structural holes will play a crucial beneficial role in these kinds of circumstances, which are most likely to be relevant to radical innovations and in the discovery phase (See also Table 5.2). The opposite situation involving limited uncertainty, which is found in the case of incremental innovations and situations involving the realization of an innovation, strong ties and dense networks appear to be more beneficial. In both cases, the object is not to have only strong or weak ties, and there will always be a mixture, although in these more clear-cut circumstances we refer to the dominant network effect. In the other cases in the matrix, it is not entirely clear from literature which mixture is the most beneficial.

\section{References}

Abuja, G. (2000), 'The duality of collaboration: inducements and opportunities in the formation of inter-firm linkages', Strategic Management Journal, 21: 317-343.

Baker, W.E. \& D. Obstfeld (1999), 'Social capital by design: structures, strategies and institutional context', In: R.Th.A.J. Leenders and S.M. Gabbay (eds), Corporate social capital and liability, Boston: Kluwer Academic Publishers.

Bruederl, J. \& P. Preisendorfer (1998), 'Network support and the business of newly founded businesses', Small Business Economics 10: 213-225.

Burt, R. S. (1992). Structural holes: the social structure of competition. Cambridge, MA: Harvard University Press.

Burt, R.S. (2000), 'The network structure of social capital', Research in Organizational Behaviour 22: 345-423.

Chell, E. \& S. Baines (2000), 'Networking, entrepreneurship and microbusiness behaviour,' Entrepreneurship \& Regional Development 12: 195-215. 
Cohen, W.M. \& D.A. Levinthal (1990), 'Absorptive capacity: a new perspective on learning and innovation,' Administrative Science Quarterly 35: 128-152.

Coleman, J. S. (1988), "Social capital in the creation of human capital”, American Journal of Sociology, 94: S95-S120.

Dosi, G. (1988), 'Sources, procedures, and microeconomic effects of innovation', Journal of Economic Literature 26: 1120-1171.

Dyson, J. (1997), Against all odds; an autobiography. Orion business books.

Elfring, T. \& W. Hulsink (2007), 'Networking by entrepreneurs: patterns of tie formation for emerging organizations', Organization Studies 28 (12): 1849-1872.

Floyd S.W \& B. Wooldridge (1999), 'Knowledge creation and social networks in corporate entrepreneurship: the renewal of organizational capability', Entrepreneurship Theory \& Practice 23(3): 123-143

Gabbay, S.M. \& R.Th.A.J. Leenders (1999), 'Corporate social capital: the structure of advantage and disadvantage', In: R.Th.A.J. Leenders and S.M. Gabbay (eds), Corporate social capital and liability, Boston: Kluwer Academic Publishers.

Gargiulo, M. and M. Benassi, 1999, 'The dark side of social capital', In: R.Th.A.J. Leenders and S.M. Gabbay (eds), Corporate social capital and liability, Boston: Kluwer Academic Publishers.

Granovetter, M. (1995), Getting a job. A study of contacts and careers (2 $2^{\text {nd }} e d$, 1974). University of Chicago Press.

Granovetter, M. (1985), 'Economic action and social structure: the problem of embeddedness', American Journal of Sociology, 91: 481-510.

Granovetter, M.S. (1973), 'The strength of weak ties', American Journal of Sociology, 78: 1360-1380. 
Hansen, M. T. (1999), 'The search-transfer problem: the role of weak ties in sharing knowledge across organization subunits', Administrative Science Quarterly, 44: 82111.

Hargadon, A.(2003), How breakthroughs happen? The surprising truth about how companies innovate. Harvard Business School Press.

Hargadon, A.(1998), 'Firms as knowledge brokers', California Management Review 40: 209227.

Hargadon, A. \& R.I Sutton (1997), 'Technology brokering and innovation in a product development firm', Administrative Science Quarterly 42: 716-749.

Hite, J.M.(2003), 'Patterns of multidimensionality among embedded network ties: a typology of relational embeddedness in emerging entrepreneurial firms', Strategic Organization 1: 9-49.

Jones, O. \& S. Conway (2004), 'The international reach of entrepreneurial social networks: the case of James Dyson in the UK', In: H. Etemad (ed), International entrepreneurship in small and medium size enterprises: orientation, environment and strategy. Edward Elgar. Pp.87-106.

Krackhardt, D., 1992, 'The strength of strong ties: The importance of Philos in Organizations', In: N. Nohria \& R.G. Eccles (eds), Networks and organizations: structure, form and action, HBS Press, pp.216-239.

Lee, C., K. Lee \& J.M. Pennings (2001), 'Internal capabilities, external networks, and performance: a study on technology-based ventures', Strategic Management Journal 22: 615-640.

Leenders, R.Th.A.J. \& S.M. Gabbay (eds) (1999), Corporate social capital and liability. Kluwer Academic Publishers. 
March, J.G. (1991), 'Exploration and exploitation in organizational learning,' Organization Science 2: 71-87.

McEvily, B., \& Zaheer, A. (1999), 'Bridging ties: a source of firm heterogeneity in competitive capabilitites', Strategic Management Journal 20: 1133-1156.

Menon, T. \& J. Pfeffer (2003), 'Valuing internal vs. external knowledge: explaining the preference for outsiders,' Management Science 49: 497-513.

Miner, J.B., N.R. Smith \& J.S. Bracker (1992), 'Defining the inventor-entrepreneur in the context of established typologies', Journal of Business Venturing 7: 103-113.

Nohria, N.(1992), 'Information and search in the creation of new business ventures: The case of the 128 Venture Group', In: N. Nohria \& R.G. Eccles (eds), Networks and organizations: structure, form and action, HBS Press, pp.240-261.

O’Donnell (2004), 'The nature of networking in small firms,' Qualitative Market Research: An International Journal 7 (3): 206-217.

Oerlemans, L.A.G., M.T.H. Meeus \& F.W.M. Boekema (1998), 'Do networks matter for innovation? The usefulness of the economic networks approach in analysing innovation', Tijdschrift voor Economische en Sociale Geografie 89: 298-309.

Powell, W.W., K.W. Koput \& L. Smith-Doerr (1996), 'Interorganizational collaboration and the locus of Innovation: networks of learning in biotechnology,' Administrative Science Quarterly 41: 116-145.

Quinn, J.B. \& J.J. Baruch \& K.A. Zien (1997), Innovation explosion. Using intellect and software to revolutionize growth strategies. Free Press.

Rowley, T., Behrens, D., \& Krackhardt, D. (2000), 'Redundant governance structures: an analysis of structural and relational Embeddedness in the steel and semiconductor industries', Strategic Management Journal, 21: 369-386. 
Ruef, M.(2002), 'Strong ties, weak ties and islands: Structural and cultural predictors or organizational innovation', Industrial and Corporate Change 11: 427-449.

Smith, N.R. \& J.B. Miner (1983), 'Type of entrepreneur, type of firm and managerial motivation: implications for life cycle theory', Strategic Management Journal 4: 325340.

Stam W \& T. Elfring (2008), 'Entrepreneurial orientation and new venture performance: the moderating role of intra- and extra-industry social capital', Academy of Management Journal 51(1): 97-111

Stinchcombe, A. (1965), ‘Social structure and organizations’, In J. G. March (ed.), Handbook of Organizations. Chicago: Rand McNally, pp. 153-193.

Stuart, T. E., Hoang, H., \& Hybels, R. C. (1999), 'Interorganizational endorsements and the performance of entrepreneurial ventures', Administrative Science Quarterly 44: 315349.

Uzzi, B. (1997), Social structure and competition in inter-firm networks: the paradox of embeddedness', Administrative Science Quarterly, 42: 35-67.

Van De Ven, A.H. (1986), 'Central problems in the management of innovation', Management Science, 32: 590-607.

Van De Ven, A.H.(1993), 'The development of an infrastructure for entrepreneurship', Journal of Business Venturing 8: 211-230.

Weick, K.E. (1979), The social psychology of organizing. Random House.

Yli-renko, H., Autio, E., \& Sapienza, H. J. (2001), 'Social capital, knowledge acquisition, and knowledge exploitation in young technology-based firms, Strategic Management Journal 22: 567-613. 
Table 5.1: Overview of selected studies

\begin{tabular}{|c|c|c|c|c|}
\hline Authors & Research question & Key concepts & Setting and data & Findings \\
\hline Stuart et al. (1999) & $\begin{array}{l}\text { How does the prominence of a new } \\
\text { venture's alliance partners affect its } \\
\text { legitimacy and performance? }\end{array}$ & $\begin{array}{l}\text { Legitimacy } \\
\text { Partner prominence } \\
\text { Time to IPO }\end{array}$ & $\begin{array}{l}301 \text { U.S. venture-capital- } \\
\text { backed biotechnology firms }\end{array}$ & $\begin{array}{l}\text { Ventures with prominent strategic } \\
\text { alliance partners and equity investors } \\
\text { go to IPO faster and earn greater } \\
\text { valuations. }\end{array}$ \\
\hline Ruef (2002) & $\begin{array}{l}\text { How does the tendency of } \\
\text { entrepreneurs to engage in innovation } \\
\text { relate to their social embeddedness? }\end{array}$ & $\begin{array}{l}\text { Innovative action } \\
\text { Embeddedness } \\
\text { Team composition }\end{array}$ & $\begin{array}{l}766 \text { entrepreneurial teams } \\
\text { who attempted to start new } \\
\text { ventures }\end{array}$ & $\begin{array}{l}\text { Large, heterogeneous teams with } \\
\text { weak ties and diverse networks are } \\
\text { most innovative. }\end{array}$ \\
\hline Yli-Renko et al. (2001) & $\begin{array}{l}\text { How does social capital in firm-client } \\
\text { relations affect a firm's knowledge } \\
\text { acquisition and exploitation? }\end{array}$ & $\begin{array}{l}\text { Social capital } \\
\text { Knowledge acquisition } \\
\text { Knowledge exploitation }\end{array}$ & $\begin{array}{l}180 \text { new technology-based } \\
\text { firms based in the U.K. }\end{array}$ & $\begin{array}{l}\text { Social interaction and network ties } \\
\text { increase while relationship quality } \\
\text { reduces knowledge acquisition. }\end{array}$ \\
\hline McEvily \& Zaheer (1999) & $\begin{array}{l}\text { What explains differences in a firm's } \\
\text { competitive capabilities? }\end{array}$ & $\begin{array}{l}\text { Bridging ties } \\
\text { Strong and weak ties } \\
\text { Regional institutional ties }\end{array}$ & $\begin{array}{l}227 \text { job shop manufacturers } \\
\text { located in the Midwest U.S. }\end{array}$ & $\begin{array}{l}\text { Structural holes and regional } \\
\text { institutional linkages are positively } \\
\text { related to the acquisition of } \\
\text { competitive capabilities. }\end{array}$ \\
\hline Hite \& Hesterly (2001) & $\begin{array}{l}\text { How does the network of new firms } \\
\text { evolve from emergence to early } \\
\text { growth? }\end{array}$ & $\begin{array}{l}\text { Identity-based networks } \\
\text { Calculative networks } \\
\text { Life cycle stage }\end{array}$ & - & $\begin{array}{l}\text { As firms move from emergence to } \\
\text { early growth, their networks evolve } \\
\text { from cohesion and a few strong ties } \\
\text { to sparse with many weak ties. }\end{array}$ \\
\hline Elfring \& Hulsink (2007) & $\begin{array}{l}\text { How does the mixture of a firm's } \\
\text { strong and weak ties evolve over } \\
\text { time? }\end{array}$ & $\begin{array}{l}\text { Strong and weak ties } \\
\text { Initial conditions } \\
\text { Post-founding processes }\end{array}$ & $\begin{array}{l}32 \text { startups in the Dutch ICT } \\
\text { industry }\end{array}$ & $\begin{array}{l}\text { There are three distinct patterns of } \\
\text { network evolution: evolution, } \\
\text { renewal and revolution. }\end{array}$ \\
\hline Rowley et al. (2000) & $\begin{array}{l}\text { How does the value of weak ties and } \\
\text { structural holes depend on industry } \\
\text { conditions? }\end{array}$ & $\begin{array}{l}\text { Strong and weak ties } \\
\text { Density } \\
\text { Exploration and } \\
\text { exploitation }\end{array}$ & $\begin{array}{l}\text { Alliances in the } \\
\text { semiconductor and steel } \\
\text { industries over 1990-1997 } \\
\text { period }\end{array}$ & $\begin{array}{l}\text { Strong ties and dense networks } \\
\text { increase firm performance in } \\
\text { industries characterized by } \\
\text { exploitation, whereas the reverse is } \\
\text { true for industries emphasizing } \\
\text { exploration. }\end{array}$ \\
\hline Ahuja (2000) & $\begin{array}{l}\text { How do a firm's direct and indirect } \\
\text { ties affect its innovative } \\
\text { performance? }\end{array}$ & $\begin{array}{l}\text { (In)direct ties } \\
\text { Structural holes } \\
\text { Innovativeness }\end{array}$ & $\begin{array}{l}\text { Alliances among } 97 \text { leading } \\
\text { chemical companies over } \\
\text { 1981-1991 period }\end{array}$ & $\begin{array}{l}\text { Direct and indirect ties increase a } \\
\text { firm's innovativeness, but they are } \\
\text { substitutes. Structural holes decrease } \\
\text { a firm's innovative performance. }\end{array}$ \\
\hline
\end{tabular}


Table 5.2: Contingencies and network benefits

\begin{tabular}{|l|l|l|}
\hline Radical innovation & $\begin{array}{l}\text { Weak ties and sparse network } \\
\text { with structural holes are most } \\
\text { beneficial }\end{array}$ & $\begin{array}{l}\text { Mixture of weak and strong } \\
\text { ties in combination with a } \\
\text { particular structure }\end{array}$ \\
\hline $\begin{array}{l}\text { Incremental } \\
\text { innovation }\end{array}$ & $\begin{array}{l}\text { Mixture of weak and strong } \\
\text { in combination with } \\
\text { particular structure }\end{array}$ & $\begin{array}{l}\text { Strong ties and dense } \\
\text { network are the most } \\
\text { beneficial }\end{array}$ \\
\hline & Discovery of innovation & Realization of innovation \\
\hline
\end{tabular}




\section{Publications in the ERIM Report Series Research* in Management}

\section{ERIM Research Program: "Organizing for Performance"}

2008

Explaining Preferences and Actual Involvement in Self-Employment: New Insights into the Role of Gender Ingrid Verheul, Roy Thurik and Isabel Grilo ERS-2008-003-ORG

http://hdl.handle.net/1765/10979

Public Finance in China since the Late Qing Dynasty

Barbara Krug

ERS-2008-005-ORG

http://hdl.handle.net/1765/11287

Overoptimism among Founders: The Role of Information and Motivation

Ingrid Verheul and Martin Carree

ERS-2008-008-ORG

http://hdl.handle.net/1765/11557

Do Foreign Greenfields Outperform Foreign Acquisitions or Vice Versa? An Institutional Perspective Arjen H.L. Slangen and Jean-François Hennart ERS-2008-009-ORG

http://hdl.handle.net/1765/11558

Unemployment Benefits Crowd Out Nascent Entrepreneurial Activity

Philipp Koellinger and Maria Minniti

ERS-2008-012-ORG

http://hdl.handle.net/1765/11808

Acceleration of Technology Adoption within Firms: Empirical Evidence from the Diffusion of E-business Technologies Philipp Koellinger and Christian Schade

ERS-2008-013-ORG

http://hdl.handle.net/1765/11809

Belbin Revisited: The Construct Validity of the Interplace II Team Role Instrument

Dirk van Dierendonck and Rob Groen

ERS-2008-017-ORG

http://hdl.handle.net/1765/12123

China's Institutional Architecture: A New Institutional Economics and Organization Theory Perspective on the Links between Local Governance and Local Enterprises

Barbara Krug and Hans Hendrischke

ERS-2008-018-ORG

http://hdl.handle.net/1765/12191

Ethics Programs and Ethical Cultures: A Next Step in Unraveling their Multi-Faceted Relationship

Muel Kaptein

ERS-2008-020-ORG

http://hdl.handle.net/1765/12192

Entrepreneurship Education and Training in a Small Business Context: Insights from the Competence-based Approach Thomas Lans, Wim Hulsink, Herman Baert and Martin Mulder

ERS-2008-028-ORG

http://hdl.handle.net/1765/12466 
The Relationship between Technology, Innovation, and Firm Performance: Empirical Evidence on E-Business in Europe Philipp Koellinger

ERS-2008-031-ORG

http://hdl.handle.net/1765/12469

The Relationship between Ethical Culture and Unethical Behavior in Work Groups: Testing the Corporate Ethical Virtues Model

Muel Kaptein

ERS-2008-037-ORG

http://hdl.handle.net/1765/12783

Influence Costs in Agribusiness Cooperatives: Evidence from Case Studies

Constantine lliopoulos and George Hendrikse

ERS-2008-040-ORG

http://hdl.handle.net/1765/12872

The Locus of Innovation in Small and Medium-sized Firms: The Importance of Social Capital and Networking in Innovative Entrepreneurship

Willem Hulsink, Tom Elfring and Wouter Stam

ERS-2008-041-ORG

http://hdl.handle.net/1765/12873

* A complete overview of the ERIM Report Series Research in Management: https://ep.eur.nl/handle/1765/1

ERIM Research Programs:

LIS Business Processes, Logistics and Information Systems

ORG Organizing for Performance

MKT Marketing

F\&A Finance and Accounting

STR Strategy and Entrepreneurship 